DOI $10.35381 / \mathrm{cm} . v 7 \mathrm{i} 2.505$

\title{
La auditoría social en el contexto de la economía popular y solidaria
}

Social auditing in the context of the popular and solidarity economy

\author{
Blanca Esthela Jumbo-Soto \\ blanca.jumbo@ucacue.edu.ec \\ Universidad Católica de Cuenca, Cuenca \\ Ecuador \\ https://orcid.org/0000-0002-3362-9265 \\ Juan Carlos Erazo-Álvarez \\ jcerazo@ucacue.edu.ec \\ Universidad Católica de Cuenca, Cuenca \\ Ecuador \\ https://orcid.org/0000-0001-6480-2270
}

Recibido: 20 de mayo de 2021

Aprobado: 25 de agosto de 2021 


\title{
RESUMEN
}

La auditoría social se ha transformado en una herramienta clave para el control y verificación de la implementación de programas con la participación activa de los grupos de interés, por ello, es considerada como un proceso que permite evaluar la eficiencia social y comportamiento ético frente a los objetivos sociales establecidos, de manera que los resultados obtenidos se conviertan en insumos para mejorar a futuro. En este contexto, la presente investigación tiene por objetivo diseñar un modelo de auditoría social como herramienta de medición del desempeño organizacional de la Asociación de Producción Textil NAPOTEX ASOPROTEXNAP del cantón Tena. Se aplicó un estudio no experimental con alcance descriptivo. Esta organización forma parte de la economía popular y solidaria, por lo que, es importante valorar el cumplimiento de sus derechos, obligaciones y beneficios de las personas que la integran, para este fin.

Descriptores: Política; derecho y economía; contabilidad de costes; reducción de costes. (Palabras tomadas de Tesauro Unesco).

\begin{abstract}
The social audit has become a key tool for the control and verification of the implementation of programs with the active participation of stakeholders, therefore, it is considered as a process that allows evaluating social efficiency and ethical behavior in the face of established social objectives, so that the results obtained become inputs to improve in the future. In this context, the present research aims to design a social audit model as a tool for measuring organizational performance of the NAPOTEX ASOPROTEXNAP Textile Production Association of the Tena canton. A non-experimental study with descriptive scope was applied. This organization is part of the popular and solidarity economy, so it is important to assess the fulfillment of their rights, obligations and benefits of the people who make it up, for this purpose.
\end{abstract}

Descriptors: Politics; law and economics; cost accounting; cost reduction. (Words taken from Thesaurus Unesco). 


\section{INTRODUCCIÓN}

A partir de mediados del siglo XX se presentaron dificultades en torno a la necesidad de determinar la transparencia en la rendición de cuentas en todos los ámbitos, identificar posibles malas praxis, debilidades en sistemas de control interno y observaciones sobre el prestigio externo empresarial (Poblador-Fernández \& Porta-Jacques, 2017). Situación que generó que en Estados Unidos durante el año 1940 se aplique la auditoría social, demostrando su importancia mediante la entrega de un informe final con los hallazgos.

A partir de esta situación, se plantea el proceso de auditoría social como una herramienta para evaluar la actuación social de las organizaciones, basada en 6 principios: equidad, cooperación, trabajo, sin fines de lucro, cuidado ambiental y compromiso con el entorno (Poblador-Fernández \& Porta-Jacques, 2017); además, faculta a una organización, analizar y medir su eficacia social y comportamiento ético frente a los objetivos planteados. Cabe resaltar, que es una herramienta que permite cumplir con la medición, evaluación y aplicación de medidas correctivas sobre el impacto social y solidario relacionado con sus propósitos y valores, así como los otros actores implicados.

Se debe considerar que la crisis económica globalizada conllevó a que los grupos de interés de las organizaciones se vuelvan más exigentes y con expectativas cada vez mayores, sobre la utilización eficiente de los recursos. Del mismo modo, el desempeño empresarial $u$ organizacional es un tema complejo, debido a que se toman en consideración varias características que intervienen en ésta, por cuanto, se transforma en un tema con diferentes aspectos (De-la-Garza-Carranza, Zavala-Berbena, \& LópezLemus, 2017).

En los países en desarrollo de Latinoamérica, los organismos estatales se han preocupado del establecimiento de protocolos que ayuden a mejorar el desempeño empresarial de las organizaciones; sin embargo, a pesar de los esfuerzos, existen casos en que las organizaciones no respetan las necesidades de sus grupos de interés (OjedaHidalgo, López-Salazar, \& Álvarez-Orozco, 2019). 
De forma particular, En Ecuador, en el sector de la economía popular y solidaria, las asociaciones tienen pocos años de trayectoria, por la alta competitividad del mercado, recursos económicos limitados u oferta de productos con características similares; esto ha generado que las organizaciones, trabajen con pocas herramientas de gestión, dando paso a la falta de información para medir el desempeño organizacional frente a los objetivos sociales establecidos para el grupo de interés (León, Gallegos, Vallejos, Guerrero, \& Acosta, 2020).

En relación con la situación expuesta, el problema de investigación planteado es el siguiente: ¿cómo medir el desempeño organizacional de la Asociación de Producción Textil NAPOTEX ASOPROTEXNAP del cantón Tena, frente a los objetivos sociales que han establecido para su grupo de interés?, en consecuencia, el objetivo del estudio es diseñar un modelo de auditoría social para la medición del desempeño organizacional de la Asociación de Producción Textil NAPOTEX ASOPROTEXNAP del cantón Tena, frente a los objetivos sociales que han establecido para su grupo de interés.

\section{Referencial teórico}

\section{La importancia de la responsabilidad social en las organizaciones}

A finales del siglo XX en Estados Unidos y Europa se generó un gran interés sobre los procesos de la responsabilidad social en las empresas y durante la última década, ha crecido el valor en las administraciones públicas, privadas y todo tipo de organizaciones de todo el mundo, tanto en países desarrollados como en países en vías de desarrollo, por ejemplo en Ecuador, su enfoque versa sobre la generación de trabajo, estimulación de la cohesión social, reducción de la pobreza y el logro de modelos de desarrollo sostenible (Villalba-Eguiluz, Arcos-Alonso, Pérez-de-Mendiguren, \& Urretabiskaia-Gil, 2020). En el contexto ecuatoriano, a partir de la Constitución de la República del Ecuador del año 2008 y la aprobación de la Ley Orgánica de Economía Popular y Solidaria en el año 2011 , se ha ido fomentando la responsabilidad social. 
La responsabilidad social es identificada como el conjunto de actividades que generan valor mediante la relación entre las personas y la naturaleza; atención de los grupos de interés sobre los recursos; independencia y libertad en la administración y maximización en la calidad del bien o servicio ante la búsqueda de rendimientos (Montes, 2016; Aguinis, Villamor, \& Gabriel, 2020; Albert-Pires, Mourão-Arslan, Bayma-de-Oliveira, \& Puppim-deOliveira, 2020), permitiendo obtener distintos resultados en el área social, económico y ambiental.

Si bien determinar la conceptualización, los principios e importancia de la responsabilidad social es indispensable, un elemento significativo son los stakeholders o grupos de interés que forman parte de la actitud responsable con un enfoque social, establecido por una persona o grupo de personas que tienen un interés en las organizaciones, en razón de que se pueden ver afectados por las operaciones que se efectúen (Moreno-Prieto, s.f.; Asociación Española de Contabilidad y Administración de Empresas, 2016). Partiendo de lo expuesto, el diálogo con los grupos de interés se transforma en una herramienta clave para aplicar medidas correctivas con el fin de instaurar una gestión responsable, es decir, que la responsabilidad social se integre a la estrategia institucional y se mantenga una comunicación eficaz con todos los involucrados tanto internos como externos.

En Ecuador, para normar el trabajo de las entidades bajo el control de la Superintendencia de Economía Popular y Solidaria (SEPS), se aprobó la Ley Orgánica de Economía Popular y Solidaria en el año 2011 y su Reglamento en el año 2012, y se generó la última actualización en el año 2020; estableciendo en su artículo 167 las obligaciones de este sector, entre las principales se encuentran: ejecutar las tareas presentadas en el estatuto de la entidad encaminadas al propósito social, gestionar la contabilidad de conformidad con la normativa vigente del organismo rector; $y$, observar la reglamentación para el manejo de la operación socio-económica (Superintendencia de Economía Popular y Solidaria (SEPS), 2020). 
En Latinoamérica, se presenta un modelo de gestión de responsabilidad social empresarial chileno, el cual se basa en un sistema de mejora continua a través de los procesos de planificar $(P)$, hacer $(H)$, verificar $(V)$ y actuar $(A)$; en cambio, en Colombia existe el modelo en red de responsabilidad social que propone un proceso descentralizado con la intervención de todos los actores involucrados en los procesos de responsabilidad social (Luque-González, Ordóñez-Salcedo, \& Ruales-Acosta, 2017). Otra de las herramientas existentes es la aplicación de la auditoría social para indagar, conocer y establecer si todos los recursos están siendo utilizados para beneficiar a la colectividad y buscar la mejora en la calidad de vida de las partes interesadas (Buvollen, Mendoza, Reyes, \& Williams, 2006; Red de Economía Alternativa y Solidaria Euskadi (REAS), 2011).

\section{Operacionalización de la auditoría social en las organizaciones}

El origen de la auditoría social data de los años 70 como respuesta a las demandas de los consumidores y grupos ambientales en Estados Unidos y países europeos, mediante la aplicación de métodos para involucrar de forma activa a las partes interesadas en la toma de decisiones; después, en la década de los 80 , la auditoría social se extendió del sector privado al sector público para cubrir las necesidades de las nuevas tendencias emergentes como rendición de cuentas, manejo de recursos y transparencia (EspinozaOrtega, Narváez-Zurita, \& Erazo Álvarez, 2019); asimismo, en la medida en que los países se iban fortaleciendo en la gobernanza democrática en la década de los 90 y el año 2000, la auditoría social ganó mayor importancia por la preocupación de la existencia de prácticas corruptas y mala administración (Berthin-Siles, 2011).

La auditoría social se ha transformado en una herramienta clave para el control y verificación en la implementación de programas con la participación activa de los grupos de interés (Gunjan-Kumar \& Josyula-Prasuna, 2016), por ello, es considerada como un proceso que permite evaluar la eficiencia social y comportamiento ético frente a los 
objetivos sociales establecidos, de manera que los resultados obtenidos se convierten en insumos para mejorar a futuro (Berthin-Siles, 2011; Ministry of Housing \& Urban Poverty Alleviation, 2017; Servicio de Acreditación Ecuatoriano, 2018), por otro lado, (Sáenz-deUgarte, 2016) añade que posibilita demostrar los beneficios y limitaciones sociales de las organizaciones, en busca de consolidar la identidad propia.

Bajo las premisas expuestas, la importancia de la auditoría social radica en la caracterización de las organizaciones mediante la evaluación de la dimensión socioeconómica y la verificación de la transparencia del comportamiento ético y cumplimiento de los objetivos sociales (Poblador-Fernández \& Porta-Jacques, 2017), además, es un elemento clave para incrementar la aportación de las empresas al bien común y progreso social (Gil-Fabra, 2019).

Así mismo, la auditoría social desempeña funciones amplias y abarca varias áreas (Berthin-Siles, 2011), entre las más importantes están: a) evaluar las brechas socioeconómicas; b) crear conciencia entre los beneficiarios y proveedores de los servicios sociales y productivos; c) asegurar la transparencia de la información en la implementación de las políticas; d) medir el impacto ambiental de las operaciones; y e) permitir que los grupos de interés ejerzan sus derechos y participen activamente.

Por otro lado, se reconoce que las fases que se deben cumplir en una auditoría social son la planificación, ejecución y cierre (Arens-Alvin, Elder-Randal, \& Beasley-Mark, 2007; Benavides-Echeverría, Acosta-Padilla, \& Lozada-Orejuela, 2017). La planificación permite el conocimiento de la empresa e identificación de los componentes principales, especificación del objetivo, alcance y herramientas que se van a aplicar durante el examen. En la ejecución se efectúa la recolección y análisis de información y la generación de los documentos soporte de los hallazgos. Por último, el cierre es la fase donde se realiza la emisión del dictamen de auditoría social y se desarrolla el seguimiento de la implementación de las recomendaciones. Sin embargo, de acuerdo con un análisis efectuado en el año 2011 por el Centro Regional para América Latina y el Caribe, 


\section{CIENCIAMATRIA}

Revista Interdisciplinaria de Humanidades, Educación, Ciencia y Tecnología

Año VII. Vol. VII. N². Edición Especial II. 2021

Hecho el depósito de ley: pp201602FA4721

ISSN-L: 2542-3029; ISSN: 2610-802X

Universidad Nacional Experimental Francisco de Miranda (UNEFM). Santa Ana de Coro. Venezuela

Blanca Esthela Jumbo-Soto; Juan Carlos Erazo-Álvarez

Panamá, la implementación del proceso de la auditoría social se basa en que contribuye a informar e involucrar a los grupos de interés sobre el cumplimiento de los objetivos sociales, mediante la consecución de 4 fases de auditoría (ver tabla 1).

\section{Tabla 1.}

Fases de auditoría social.

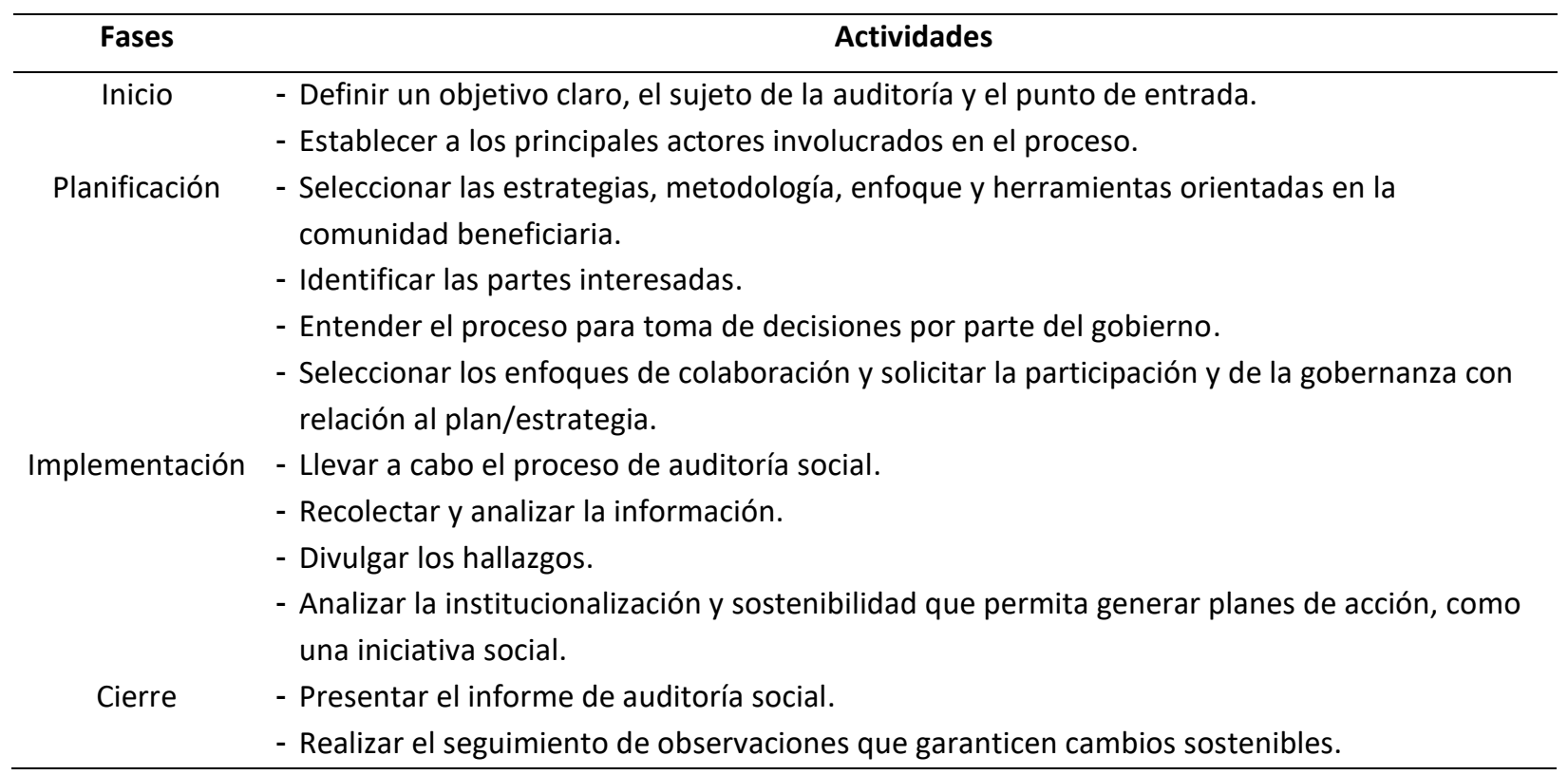

Adaptado de: Berthin-Siles (2011).

El proceso de auditoría debe ser aplicado de forma estructurada y sistemática, empleando las fases señaladas, las cuales responden a demandas de control de cada organización; y con ello, la presentación de hallazgos y acciones correctivas que servirán como un escalón para la observancia del objeto social determinado. 


\section{Preceptos para la aplicación de la auditoría social}

En la actualidad, la Red de Economía Alternativa y Solidaria Euskadi (REAS) continúa realizando auditorías sociales y generando aportes a las organizaciones de Economía Social y Solidaria asociadas, es por ello que, a fines del año 2020, ante la situación extrema que se vive a nivel mundial se efectuó un análisis del impacto del COVID-19, partiendo desde la hipótesis que la economía solidaria puede ser un factor clave para la reconstrucción del modelo socio-económico, con el propósito de conseguir información valiosa y estratégica que debe ser referida en nuevos procesos de auditoría (Red de Economía Alternativa y Solidaria Euskadi (REAS), 2020). También, ante el surgimiento de la pandemia y las restricciones a nivel internacional y local, junto con la necesidad de efectuar auditorías inmediatas, generaron que las firmas de auditoría incrementen el uso de la tecnología y efectúen sus revisiones de forma remota, obligando a modernizar los procesos de auditoría.

Asimismo, es importante señalar que en la actualidad la innovación y la transformación son el foco de atención de las organizaciones y de las firmas de auditoría, sin embargo, según (Roy-Litzenberg \& Carrie-Ramírez, 2020) la auditoría remota no es un reemplazo de la auditoría presencial, en su lugar, debe ser considerada como una garantía en ciertas circunstancias especiales, por esta razón, los auditores deben estar preparados para este tipo de escenarios.

Para la aplicación de auditoría, revisión y otros encargos de aseguramiento, el Consejo de Normas Internacionales de Auditoría y Aseguramiento (IAASB) emitió durante el año 2018 la versión actualizada en español del Manual de Pronunciamientos Internacionales de Control de Calidad, Auditoría, Revisión, otros encargos de Aseguramiento y Servicios Relacionados, el cual incluye las Normas Internaciones de Auditoría (NIA) y las Normas Internacionales de Encargos de Aseguramiento (NIEA), que permiten conseguir la documentación adecuada orientada en la formación del juicio profesional, y por consiguiente, maximizar el nivel de confianza de los grupos de interés a quienes se 
presenta el informe final (International Auditing and Assurance Satndards Board (IASSB), 2018), (ver tabla 2).

Tabla 2.

Normas internacionales aplicables al proceso de auditoría social .

\begin{tabular}{cl}
\hline Norma/Sección & \multicolumn{1}{c}{ Relacionada con } \\
\hline NIA 210 & Acuerdo de los términos de encargo de auditoría. \\
NIA 300 & Planificación de la auditoría. \\
NIA 315 & Identificación y valoración de riesgos. \\
NIA 320 & Materialidad en la planificación y ejecución. \\
NIA 520 & Análisis de datos financieros y no financieros. \\
NIA 610 & Consideraciones del trabajo en auditoría interna. \\
NIA 620 & Uso del trabajo desarrollado por un experto. \\
NIA 706 & Comunicaciones adicionales. \\
NIEA 3000 & Trabajos de aseguramiento diferentes a revisiones financieras. \\
\hline
\end{tabular}

Adaptado de: International Auditing and Assurance Satndards Board (IASSB) (2018).

Por consiguiente, se puede determinar la existencia de varios lineamientos que guían el trabajo del profesional ejerciente desde que se establece el acuerdo hasta las comunicaciones adicionales que se generen en el proceso de auditoría social, información que permitiré disponer de elementos para generar una medición del desempeño organizacional de una entidad durante un período de tiempo establecido.

\section{Aportes técnicos del desempeño organizacional}

En la actualidad las empresas atraviesan por grandes retos generados por los cambios externos e internos constantes en un entorno globalizado, añadido al incremento de exigencias por los clientes en lo referente a los productos y servicios de calidad, lo cual obliga a los actores de cada empresa a encontrar nuevas estrategias para garantizar el éxito general; para ello, es imprescindible indicar que el precepto fundamental del desempeño organizacional es la evaluación de las organizaciones, en razón de que, 
proporciona información cuantitativa y cualitativa necesaria para determinar el nivel de calidad de las actividades empresariales (Coaquira-Tuco, 2018).

Según lo señalado, el desempeño organizacional está relacionado con la efectividad y eficiencia de la organización respecto de sus resultados financieros y no financieros (Ting-Peng, Jun-Jer, \& Chih-Chung, 2010; Muthuveloo, Shanmugam, \& Teoh, 2017; Daft, 2019; Bernal-González, Pedraza-Melo, \& Castillo-Hernández, 2020), es considerado como multidimensional y refleja de forma más integral el desempeño de la entidad. Este constructo está relacionado con el comportamiento y desempeño de los empleados que son necesarios para los objetivos planteados por la empresa. Al respecto, se pueden destacar dos aspectos fundamentales: el análisis de los resultados integrales alineado con el cumplimiento de las metas; y, mantener una visión estratégica que permita promover la calidad empresarial, enfocándose tanto en factores objetivos como subjetivos.

Asimismo, la importancia del desempeño organizacional se basa en: a) conocer si las acciones correctivas aplicadas logran los resultados planificados; b) facilitar un proceso sistemático y continuo para evaluar los productos, servicios y procesos de la empresa para la toma de decisiones asertivas; c) vincular los procesos a la visión estratégica; d) dirigir a la transformación organizacional; e) maximizar el nivel de calidad; y, f) promover la creatividad e innovación (Coaquira-Tuco, 2018).

Se puede establecer que la gestión se relaciona con la intención para implementar mejoras y el desempeño adecuado está direccionado con el cumplimiento de los objetivos y de la estrategia institucional, por ello, la meta de los sistemas de medición es implantar la estrategia, permitiendo manejar factores básicos de éxito en el presente y futuro, otorgando un enfoque integral de toda la organización (Salgado-Castillo \& CalderónPinzón, 2014). 
La gestión y medición del desempeño organizacional proporciona un enfoque crítico, útil y necesario para el manejo de cualquier tipo de empresa, aspectos claves e indispensables para comparar el nivel de desempeño real con el desempeño planificado; por cuanto, facilita la colaboración con las mejoras determinadas. Estos procesos deben ser tomados como aspectos formales que los directivos usan para discernir con mayor confiabilidad las oportunidades de mejora (Hernández-Madrigal, 2017), permitiendo equilibrar los intereses de los distintos grupos de interés que se presentan en la figura 1. Como se observa, se incluyen los diferentes grupos de interés y lo que esperan de la organización, se aprecia que en algunas ocasiones ciertos factores se cruzan presentándose dificultades para cumplir de manera simultánea con cada uno de ellos, por consiguiente, es indispensable que los administradores evalúen los intereses de esos grupos y que les permita generar satisfacción aun cuando sea en un nivel mínimo; por ejemplo, la comunidad y los acreedores comparten el interés de la responsabilidad social, lo que le obliga al administrador a ser cauteloso con las decisiones que tome en cada situación de la organización.

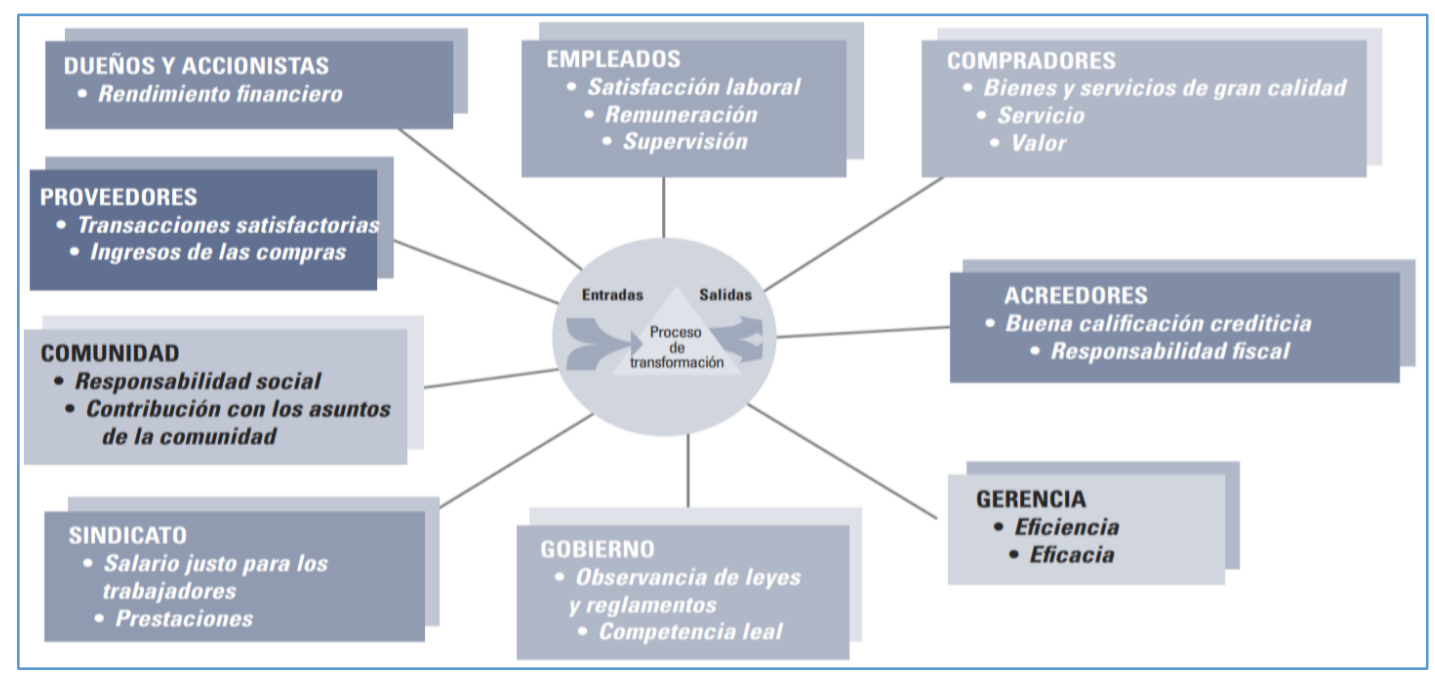

Figura 1. Intereses de los stakeholders.

Fuente: Daft (2019). 
Bajo estas premisas, se puede determinar que las entidades de la economía popular y solidaria se asocian con un objetivo social, buscando un equilibrio entre el manejo de los recursos financieros y el aporte para mejorar las condiciones de vida de los grupos de interés que forman parte de este sector. En este contexto, es indispensable tener claros cuáles son los intereses planteados por las partes interesadas sobre todo aquellos que están alineados con el desarrollo comunitario, análisis que determinará procesos de mejora que apuntan al éxito empresarial a corto y largo plazo. De ello, resulta necesario señalar a la auditoría social como una herramienta de medición que incluye factores financieros y no financieros, lo que hace que se obtenga un análisis socio-económico, cuyos resultados permitirán aportar con la rendición de cuentas a los stakeholders de este sector y como factor clave para la determinación de propuestas de mejora enfocados en el cumplimiento total de los objetivos sociales.

\section{METODOLOGÍA}

La investigación fue de tipo descriptiva con diseño no experimental, debido a que se describió el fenómeno sin ninguna manipulación de la realidad. (Hernández, Fernández, \& Baptista, 2014), la investigación se inició con el marco teórico y finalizó con la propuesta para el cumplimiento del objetivo de estudio. La finalidad fue transversal, en razón de que se recopiló la información en un solo momento del tiempo (Zhañay-Soliz, Erazo-Álvarez, \& Narváez-Zurita, 2019).

Las técnicas e instrumentos que se aplicaron fueron: encuesta mediante un cuestionario y observación con las guías de observación. Para determinar la fiabilidad del cuestionario se aplicó la razón de validez de contenido (RVC) a través de la valoración de expertos, obteniendo un coeficiente de 0.81 , que determinó que los ítems son suficientes para medir las dimensiones planteadas en el estudio. La unidad de análisis fue la Asociación de Producción Textil NAPOTEX ASOPROTEXNAP, ubicada en el cantón Tena, y su universo de estudio estuvo conformado por 11 funcionarios del nivel directivo y 14 socios. 


\section{RESULTADOS}

Las organizaciones del sector de la economía popular y solidaria en Ecuador han ganado importancia por su enfoque en el ser humano y en la colectividad, por tanto, es indispensable generar vías de supervisión integral que permitan determinar el cumplimiento de los objetivos sociales establecidos. Entre los principales resultados obtenidos mediante el diagnóstico, están los siguientes:

Talento humano: todas las organizaciones deben tener claramente establecidas las políticas para la gestión del talento humano, por cuanto esto genera una mejor calidad de vida para todo el personal. En este sentido, el $100 \%$ de los encuestados indicó que la asociación les permite aprender y progresar como personas mediante la concientización del trabajo en equipo, suministro de herramientas necesarias para cumplir adecuadamente las funciones encomendadas y capacitaciones relacionadas con la seguridad y salud ocupacional, no obstante, el $36 \%$ indican que no hay controles para minimizar los riesgos a los que están expuestos, existiendo un aspecto sobre el cual se debe trabajar para la consecución de los objetivos.

Buen gobierno corporativo: para contribuir con el desarrollo económico sostenible es necesario contar con una estructura y procesos que guíen a la empresa a la consolidación de una imagen responsable ante los grupos de interés. Al respecto, el nivel directivo y los socios manifestaron que la asociación cuenta con una estructura establecida y sus funciones son normadas a través de manuales de funciones y control interno. Pese a este resultado, el $36 \%$ de los encuestados indicaron que no tienen identificados los grupos de interés de la asociación.

Ambiente legal: para que una organización pueda operar sin ningún impedimento es importante determinar el contexto legal que debe tener presente en el desarrollo de sus operaciones. Sobre esta dimensión de estudio, el 76\% afirma conocer la Ley Orgánica de Economía Popular y Solidaria y su reglamento, normativa principal para las 
organizaciones bajo el control de la SEPS, lo que permite dar cumplimiento a todos los aspectos legales enfocados en los objetivos sociales, así pues, esta situación genera que la asociación no tenga juicios, litigios ni sanciones en las que se encuentre involucrada por incumplimiento de la normativa vigente.

Sostenibilidad de la asociación: en la actualidad, la mayoría de organizaciones buscan incrementar el impacto positivo en el factor económico, en la comunidad y medioambiente a corto y largo plazo. Al respecto, el $72 \%$ de los encuestados contestaron que tienen un alto nivel de compromiso para mantener las operaciones de la asociación a largo plazo, enfocados en la calidad del producto y evaluación continua de la satisfacción de los clientes, lo que permitirá aplicar medidas correctivas en el caso de que no se cumpla con los niveles adecuados. Asimismo, el presidente indica que se está trabajando en la identificación de los principales riesgos internos y externos a los que está sometida la asociación para estructurar opciones de respuesta inmediata.

Responsabilidad social: sobre esta dimensión, el nivel directivo y socios encuestados conocen los lineamientos estratégicos que tiene la asociación como misión, visión, valores, principios y objetivos estratégicos, los cuales mantienen una corresponsabilidad con la comunidad y medioambiente, tal como lo requiere la normativa de la SEPS, este aspecto, ha permitido que la asociación contribuya principalmente con sus grupos de interés en los aspectos de trabajadores saludables y motivados, salarios justos, incremento de empleo, equidad de género, seguridad y salud en el trabajo, cuidado y preservación del medioambiente, entre otros beneficios. Sin embargo, un 32\% de los encuestados indica que no se cuenta con políticas claras para resguardar el medioambiente y el $20 \%$ desconoce la existencia de políticas medioambientales. 
Revista Interdisciplinaria de Humanidades, Educación, Ciencia y Tecnología

Año VII. Vol. VII. N². Edición Especial II. 2021

Hecho el depósito de ley: pp201602FA4721

ISSN-L: 2542-3029; ISSN: 2610-802X

Universidad Nacional Experimental Francisco de Miranda (UNEFM). Santa Ana de Coro. Venezuela

Blanca Esthela Jumbo-Soto; Juan Carlos Erazo-Álvarez

\section{PROPUESTA}

A partir de los resultados obtenidos en el apartado anterior, y con la finalidad de medir el desempeño organizacional de la Asociación de Producción Textil NAPOTEX ASOPROTEXNAP del cantón Tena, se plantea un modelo de auditoría social que contiene 9 elementos, los mismos que se detallan en la figura 2.

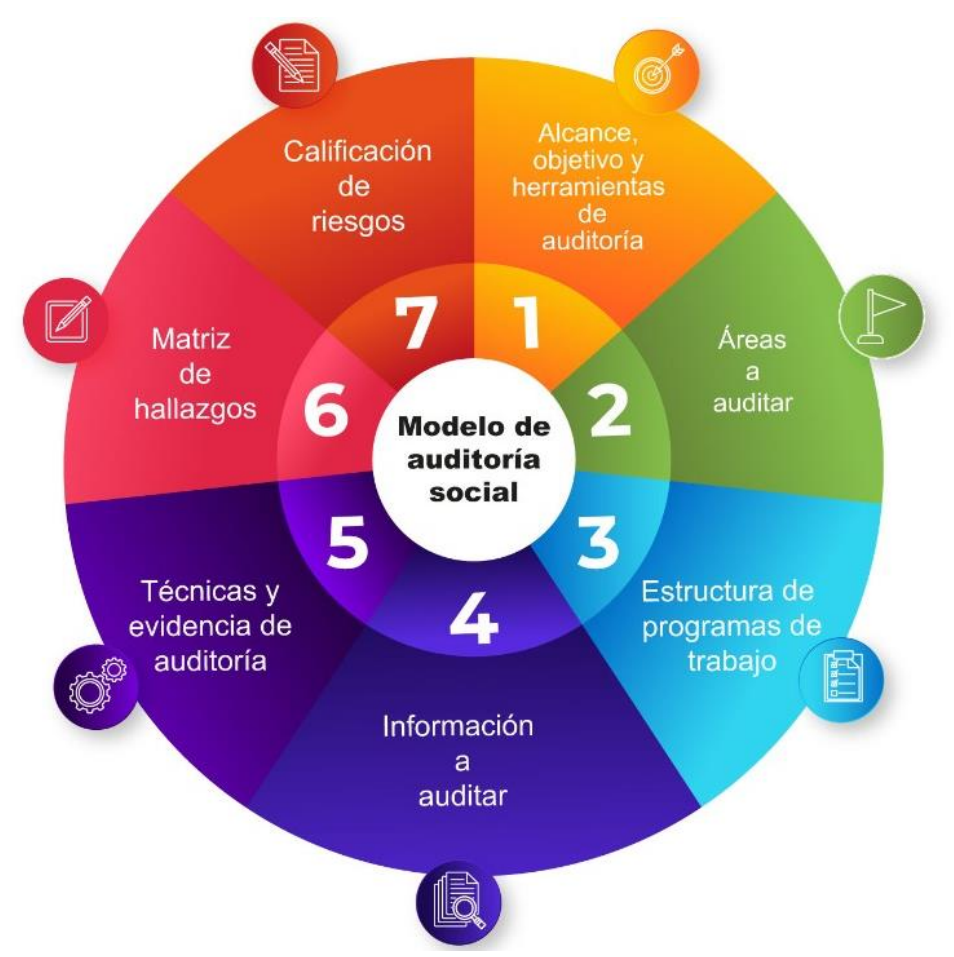

Figura 2. Modelo de auditoría social.

Elaboración: Los autores. 
Revista Interdisciplinaria de Humanidades, Educación, Ciencia y Tecnología

Año VII. Vol. VII. N². Edición Especial II. 2021

Hecho el depósito de ley: pp201602FA4721

ISSN-L: 2542-3029; ISSN: 2610-802X

Universidad Nacional Experimental Francisco de Miranda (UNEFM). Santa Ana de Coro. Venezuela

Blanca Esthela Jumbo-Soto; Juan Carlos Erazo-Álvarez

\begin{abstract}
Fase 1. Alcance, objetivos y herramientas de auditoría: El alcance, objetivos y herramientas se presentan en el plan de auditoría social (ver tabla 3).
\end{abstract}

Tabla 3.

Alcance, objetivos y herramientas de auditoría.

\begin{tabular}{|c|c|c|}
\hline \multicolumn{3}{|c|}{ Asociación de Producción Textil NAPOTEX } \\
\hline \multicolumn{3}{|c|}{ Plan de auditoría social } \\
\hline \multicolumn{3}{|c|}{ Del 1 de enero al 31 de diciembre de 2020} \\
\hline $\begin{array}{l}\text { Objetivo de la } \\
\text { auditoría }\end{array}$ & \multicolumn{2}{|c|}{$\begin{array}{l}\text { Obtener elementos de juicio suficientes para formar una opinión sobre el cumplimiento de la } \\
\text { normativa vigente aplicable a la asociación enfocada en los objetivos sociales. }\end{array}$} \\
\hline $\begin{array}{l}\text { Alcance de la } \\
\text { auditoría }\end{array}$ & \multicolumn{2}{|c|}{ Actividades administrativas y financieras durante el año $20 x x$} \\
\hline Equipo Auditor & \multicolumn{2}{|l|}{$\begin{array}{l}\text { Socio de Auditoría } \\
\text { Asistente de Auditoría }\end{array}$} \\
\hline № & Herramientas & Equipo Auditor \\
\hline 1 & $\begin{array}{l}\text { Levantamiento de información de la asociación mediante } \\
\text { entrevistas y cuestionarios. }\end{array}$ & $\begin{array}{l}\text { Socio de Auditoría } \\
\text { Asistente de Auditoría }\end{array}$ \\
\hline 2 & $\begin{array}{l}\text { Confirmaciones a socios, proveedores y clientes sobre } \\
\text { transacciones y actividades desarrolladas por la asociación. }\end{array}$ & Asistente de Auditoría \\
\hline 3 & $\begin{array}{l}\text { Verificación de documentos sobre las actividades administrativas y } \\
\text { financieras de la asociación }\end{array}$ & Asistente de Auditoría \\
\hline 4 & Aplicación de encuestas a los empleados de la asociación. & Asistente de Auditoría \\
\hline 5 & $\begin{array}{l}\text { Aplicación de check list sobre el impacto ambiental del proceso } \\
\text { productivo de la asociación y de sus socios. }\end{array}$ & Asistente de Auditoría \\
\hline 6 & Revisión del proceso de producción. & Asistente de Auditoría \\
\hline 7 & $\begin{array}{l}\text { Evaluación de las conclusiones a las que llega el auditor con base } \\
\text { en la información recopilada. }\end{array}$ & Socio de Auditoría \\
\hline
\end{tabular}

\title{
Elaboración: Los autores.
}




\section{CIENCIAMATRIA}

Revista Interdisciplinaria de Humanidades, Educación, Ciencia y Tecnología

Año VII. Vol. VII. N². Edición Especial II. 2021

Hecho el depósito de ley: pp201602FA4721

ISSN-L: 2542-3029; ISSN: 2610-802X

Universidad Nacional Experimental Francisco de Miranda (UNEFM). Santa Ana de Coro. Venezuela

Blanca Esthela Jumbo-Soto; Juan Carlos Erazo-Álvarez

Fase 2. Áreas a auditar: las áreas sensibles que se analizan en la auditoría social de la asociación se presentan en la matriz de doble entrada (ver tabla 4).

Tabla 4.

Matriz de la determinación de las áreas a auditar.

\begin{tabular}{ll}
\hline \multicolumn{1}{c}{ Área } & \multicolumn{1}{c}{ Descripción } \\
\hline $\begin{array}{l}\text { Gobernanza corporativa } \\
\text { Mercado social }\end{array}$ & $\begin{array}{l}\text { Junta Directiva, Junta de Vigilancia, clientes y otras partes interesadas. } \\
\text { Clientes, proveedores (socios constituyentes y proveedores), prácticas de } \\
\text { comercio justo. }\end{array}$ \\
Contabilidad & $\begin{array}{l}\text { Estado de situación financiera, estado de resultados, estado de cambios en el } \\
\text { patrimonio, estado de flujos de efectivo, estado de costos de producción y } \\
\text { ventas, notas explicativas y balance social de la asociación. }\end{array}$ \\
$\begin{array}{l}\text { Talento Humano } \\
\text { Medioambiente }\end{array}$ & $\begin{array}{l}\text { Impactón de trabajos, condiciones laborales y sueldos y salarios } \\
\text { Impdion actividad de la asociación y de los socios y actuación en gestión }\end{array}$ \\
\hline Rendición de cuentas & $\begin{array}{l}\text { Informes presentados a la SEPS, informes presentados a los socios, informes } \\
\text { incluidos en la página web de la asociación. }\end{array}$ \\
\hline
\end{tabular}

Fuente: Los autores.

Fase 3. Estructura de programas de trabajo: los programas de trabajo a aplicar durante la ejecución de la auditoría se presentan en la tabla 5.

\section{Tabla 5.}

Programas de trabajos por área.

\begin{tabular}{|c|c|c|c|}
\hline Referencia & $\begin{array}{l}\text { Programa de } \\
\text { trabajo }\end{array}$ & Objetivo & Procedimientos principales \\
\hline GC.1. & $\begin{array}{l}\text { Gobernanza } \\
\text { corporativa }\end{array}$ & $\begin{array}{l}\text { Analizar los } \\
\text { lineamientos } \\
\text { estratégicos, } \\
\text { objetivos, procesos y } \\
\text { políticas que guían a la } \\
\text { asociación. }\end{array}$ & $\begin{array}{l}\text { 1. Levantamiento de información de la gobernanza } \\
\text { corporativa de la asociación. } \\
\text { 2. Solicitar los lineamientos estratégicos, objetivos, } \\
\text { procesos y políticas documentadas que rigen a la } \\
\text { asociación. } \\
\text { 3. Análisis de la información recopilada. }\end{array}$ \\
\hline MS.1. & Mercado social & $\begin{array}{l}\text { Verificar que las } \\
\text { actividades de la } \\
\text { asociación creen } \\
\text { oportunidades a }\end{array}$ & $\begin{array}{l}\text { 1. Obtener una muestra de los clientes, proveedores, } \\
\text { personal. } \\
\text { 2. Aplicación de un cuestionario sobre el aporte de la } \\
\text { asociación al mercado social. }\end{array}$ \\
\hline
\end{tabular}




\section{CIENCIAMATRIA}

Revista Interdisciplinaria de Humanidades, Educación, Ciencia y Tecnología

Año VII. Vol. VII. N². Edición Especial II. 2021

Hecho el depósito de ley: pp201602FA4721

ISSN-L: 2542-3029; ISSN: 2610-802X

Universidad Nacional Experimental Francisco de Miranda (UNEFM). Santa Ana de Coro. Venezuela

Blanca Esthela Jumbo-Soto; Juan Carlos Erazo-Álvarez

\begin{tabular}{|c|c|c|c|}
\hline & & $\begin{array}{l}\text { clientes, proveedores } \\
\text { y comunidad en } \\
\text { general, mediante la } \\
\text { aplicación de prácticas } \\
\text { de comercio justo. }\end{array}$ & $\begin{array}{l}\text { 3. Elaborar confirmaciones a clientes, proveedores, } \\
\text { socios y personal. } \\
\text { 4. Cruce de las prácticas de comercio justo con las } \\
\text { transacciones efectuadas por la asociación. } \\
\text { 5. Revisión de las iniciativas solidarias con los } \\
\text { stakeholders. }\end{array}$ \\
\hline C.1. & Contabilidad & $\begin{array}{l}\text { Verificar la } \\
\text { razonabilidad de las } \\
\text { cuentas contables más } \\
\text { importantes que se } \\
\text { presentan en los } \\
\text { estados financieros y } \\
\text { la claridad del balance } \\
\text { social. }\end{array}$ & $\begin{array}{l}\text { 1. Solicitar información sobre las cuentas de ventas, } \\
\text { compras e inventarios. } \\
\text { 2. Selección de una muestra sobre las transacciones } \\
\text { que se presentan durante el año 20xx. } \\
\text { 3. Revisión de los documentos que sustenten los } \\
\text { movimientos registrados contablemente sobre las } \\
\text { cuentas más importantes de la asociación según el } \\
\text { criterio del auditor. } \\
\text { 4. Determinación de las observaciones incluidas en el } \\
\text { balance social. }\end{array}$ \\
\hline TH.1 & $\begin{array}{l}\text { Talento } \\
\text { humano }\end{array}$ & $\begin{array}{l}\text { Verificar la correcta } \\
\text { administración de los } \\
\text { recursos humanos en } \\
\text { el desempeño de las } \\
\text { funciones } \\
\text { encomendadas. }\end{array}$ & $\begin{array}{l}\text { 1. Levantamiento de información sobre las funciones y } \\
\text { responsabilidades asignadas a cada cargo de la } \\
\text { asociación } \\
\text { 2. Cruce de la información sobre las funciones y } \\
\text { responsabilidades del nivel directivo de la } \\
\text { asociación con el manual aprobado por la SEPS. } \\
\text { 3. Aplicación de entrevistas a una muestra del } \\
\text { personal de la asociación sobre las condiciones } \\
\text { laborales y sueldos y salarios justos. } \\
\text { 4. Aplicación de fórmulas sobre la creación de trabajo } \\
\text { y condiciones de trabajo. }\end{array}$ \\
\hline MA.1 & Medioambiente & $\begin{array}{l}\text { Analizar si la } \\
\text { asociación dispone de } \\
\text { acciones, productos y } \\
\text { procesos productivos } \\
\text { que sean favorables } \\
\text { para el } \\
\text { medioambiente. }\end{array}$ & $\begin{array}{l}\text { 1. Análisis del monto presupuestado para programas } \\
\text { enfocados en el impacto ambiental. } \\
\text { 2. Aplicación de check list sobre el impacto ambiental } \\
\text { del proceso productivo de la asociación y de sus } \\
\text { socios. } \\
\text { 3. Analizar el valor añadido que tienen los productos y } \\
\text { procesos de la asociación, con relación al impacto } \\
\text { ambiental. }\end{array}$ \\
\hline RC.1 & $\begin{array}{l}\text { Rendición de } \\
\text { cuentas }\end{array}$ & $\begin{array}{l}\text { Verificar el } \\
\text { cumplimiento de la } \\
\text { rendición de cuentas } \\
\text { establecida en la } \\
\text { normativa vigente } \\
\text { aplicable a la } \\
\text { asociación. }\end{array}$ & $\begin{array}{l}\text { 1. Efectuar un cruce de lo requerido en el manual para } \\
\text { el cumplimiento de atribuciones y } \\
\text { responsabilidades del nivel directivo con relación a } \\
\text { la rendición de cuentas. } \\
\text { 2. Efectuar confirmaciones externas a las partes } \\
\text { interesadas sobre el acceso a la información. }\end{array}$ \\
\hline
\end{tabular}

Fuente: Los autores. 


\section{CIENCIAMATRIA}

Revista Interdisciplinaria de Humanidades, Educación, Ciencia y Tecnología

Año VII. Vol. VII. N². Edición Especial II. 2021

Hecho el depósito de ley: pp201602FA4721

ISSN-L: 2542-3029; ISSN: 2610-802X

Universidad Nacional Experimental Francisco de Miranda (UNEFM). Santa Ana de Coro. Venezuela

Blanca Esthela Jumbo-Soto; Juan Carlos Erazo-Álvarez

\section{Fase 4. Información a auditar: el balance social establecido por la SEPS es una guía para organizar la información cualitativa y cuantitativa que se evalúa, por consiguiente, se debe revisar la información señalada en la tabla 6 .}

\section{Tabla 6.}

Información a auditar.

\begin{tabular}{|c|c|c|}
\hline Área a Auditar & $\begin{array}{l}\text { Macro dimensión balance social } \\
\text { SEPS }\end{array}$ & Cómo se evalúa \\
\hline $\begin{array}{l}\text { Talento Humano y } \\
\text { Gobernanza } \\
\text { corporativa }\end{array}$ & $\begin{array}{l}\text { Categorización de socios y } \\
\text { empleados }\end{array}$ & $\begin{array}{l}\text { - Número total de socios y empleados de la cooperativa del } \\
\text { período, clasificación por edad, género, nacionalidad, entre } \\
\text { otros. }\end{array}$ \\
\hline $\begin{array}{l}\text { Talento Humano y } \\
\text { Gobernanza } \\
\text { corporativa }\end{array}$ & $\begin{array}{l}\text { Prelación del trabajo sobre el } \\
\text { capital y de los intereses } \\
\text { colectivos sobre los individuales }\end{array}$ & $\begin{array}{l}\text { - Trabajo mercantil: medición de empleos generados, revisión } \\
\text { de las etapas de contratación, rotación y estabilidad laboral, } \\
\text { - } \text { Conisión del gasto salarios, clima laboral. } \\
\text { - } \quad \text { Trabajo de formación } \\
\text { - } \quad \text { Trabajo comunitario/voluntario/para la asociación } \\
\text { - Consumo o adquisición asociativa. } \\
\text { - Comercialización en nombre de la asociación y no en } \\
\text { - } \text { nombre propio. } \\
\text { - Programas de salud preventiva o pre-pagada. } \\
\text { - Programas de bienes social basado en el presupuesto. } \\
\text { - Programas de bienestar social. } \\
\text { - Servicios de comida y transporte para los trabajadores. } \\
\text { - Programas de solidaridad asociativa no presupuestados. } \\
\text { - Programas de educación para la familia. } \\
\text { - Programas de seguro exequial. }\end{array}$ \\
\hline $\begin{array}{l}\text { Gobernanza } \\
\text { corporativa }\end{array}$ & $\begin{array}{l}\text { Asociación voluntaria, equitativa } \\
\text { y respecto a la identidad cultural }\end{array}$ & $\begin{array}{l}\text { - Importe de los ingresos por nuevas incorporaciones de } \\
\text { socios. } \\
\text { - } \text { Retiro de socios. } \\
\text { - Devolución de cuotas sociales. }\end{array}$ \\
\hline $\begin{array}{l}\text { Contabilidad, } \\
\text { gobernanza } \\
\text { corporativa, } \\
\text { ambiente legal }\end{array}$ & Autogestión y autonomía & $\begin{array}{l}\text { - Acceso a cargos institucionales. } \\
\text { - Asistencia a Asamblea: control democrático por los socios y } \\
\text { - Transiados. } \\
\text { - } \\
\text { medios para comunicar. } \\
\text { - } \text { Acuerdos con otras organizaciones externas a la Economía } \\
\text { Popular (EPS) y Solidaria y Sistema Financiero Popular y } \\
\text { Solidario (SFPS). } \\
\text { - Relación con el Estado: impuestos totales pagados, aportes } \\
\text { al Instituto Ecuatoriano de Seguridad Social (IESS), } \\
\text { subvenciones recibidas, sanciones y multas, }\end{array}$ \\
\hline
\end{tabular}




\section{CIENCIAMATRIA}

Revista Interdisciplinaria de Humanidades, Educación, Ciencia y Tecnología

Año VII. Vol. VII. N². Edición Especial II. 2021

Hecho el depósito de ley: pp201602FA4721

ISSN-L: 2542-3029; ISSN: 2610-802X

Universidad Nacional Experimental Francisco de Miranda (UNEFM). Santa Ana de Coro. Venezuela

Blanca Esthela Jumbo-Soto; Juan Carlos Erazo-Álvarez

\begin{tabular}{|c|c|c|}
\hline & & $\begin{array}{l}\text { - Estructura del patrimonio: estado de situación financiera, } \\
\text { estado de situación financiera, estado de cambios en el } \\
\text { patrimonio y flujos de efectivo. }\end{array}$ \\
\hline $\begin{array}{l}\text { Gobernanza } \\
\text { corporativa }\end{array}$ & $\begin{array}{l}\text { Participación económica y } \\
\text { solidaria, y distribución equitativa } \\
\text { de utilidades o excedentes }\end{array}$ & $\begin{array}{l}\text { - } \quad \text { Concentración de aportes sociales: } \\
\text { - } \quad \text { Utilización de utilidades y excedentes. } \\
\text { - Valor agregado cooperativo: diferencia entre ingresos y } \\
\text { compras de bienes y servicios realizados a terceros, por ser } \\
\text { ellos los que aportaron esa parte del valor. }\end{array}$ \\
\hline Rendición de cuentas & $\begin{array}{l}\text { Educación, capacitación y } \\
\text { comunicación }\end{array}$ & $\begin{array}{l}\text { - Desarrollo de las capacidades de los actores relacionados a } \\
\text { la organización. } \\
\text { - Inversión en capacitaciones. } \\
\text { - Promoción de la EPS - Respecto al monto de Gastos } \\
\text { Operativos } \\
\text { - Medios utilizados para comunicar información. }\end{array}$ \\
\hline Mercado social & $\begin{array}{l}\text { Cooperación e integración del } \\
\text { Sector Económico Popular y } \\
\text { Solidario }\end{array}$ & $\begin{array}{l}\text { - Intercooperación: solidaridad con entidades del sector de la } \\
\text { EPS y SFPS). } \\
\text { - Integración sectorial: recogidas y reguladas por un } \\
\text { convenio, generación de redes a distintos niveles. }\end{array}$ \\
\hline $\begin{array}{l}\text { Mercado social } \\
\text { Medioambiente }\end{array}$ & $\begin{array}{l}\text { Compromiso social, solidario, } \\
\text { comunitario y ambiental }\end{array}$ & $\begin{array}{l}\text { - Comercio justo: relaciones de intercambio basadas en el } \\
\text { diálogo, la transparencia, el respeto, la equidad en el } \\
\text { comercio y sobre todo el respeto a los derechos de los } \\
\text { trabajadores con precios justos y creación de un entorno de } \\
\text { trabajo seguro con conciencia ambiental. } \\
\text { - Comunidad: donaciones, actividades socioculturales, } \\
\text { educación, ayuda económica. } \\
\text { - Medioambiente: capacitaciones, actividades } \\
\text { medioambientales, montos invertidos. }\end{array}$ \\
\hline
\end{tabular}

Fuente: Los autores.

Fase 5. Técnicas y evidencia de auditoría: para ejecutar la auditoría social se requiere aplicar las técnicas de auditoría expuestas en la tabla 7 , ya que permiten obtener evidencias suficientes para respaldar los resultados obtenidos, enfocando en cada área a auditar. 


\section{CIENCIAMATRIA}

Revista Interdisciplinaria de Humanidades, Educación, Ciencia y Tecnología

Año VII. Vol. VII. N². Edición Especial II. 2021

Hecho el depósito de ley: pp201602FA4721

ISSN-L: 2542-3029; ISSN: 2610-802X

Universidad Nacional Experimental Francisco de Miranda (UNEFM). Santa Ana de Coro. Venezuela

Blanca Esthela Jumbo-Soto; Juan Carlos Erazo-Álvarez

Tabla 7.

Técnicas y evidencia de auditoría social.

\begin{tabular}{cccc}
\hline Referencia & Programa de trabajo & Técnicas de auditoría & Evidencias de auditoría \\
\hline GC.1. & Gobernanza corporativa & Indagación & Testimonial \\
& & Entrevista & Analítica \\
& & Análisis & Documental \\
MS.1. & Mercado social & Revisión selectiva & Documental \\
& & Cuestionario & Testimonial \\
& & Comparación & Analítica \\
C.1. & Contabilidad & Confirmaciones & Indagación \\
& & Revisión selectiva & Testimonial \\
& & Análisis & Documental \\
TH.1 & Talento humano & Indagación & Analítica \\
& & Comparación & Testimonial \\
& & Entrevistas & Analítica \\
& & Cálculo & \\
MA.1 & Medioambiente & Análisis & Analítica \\
& & Comprobación & Documental \\
RC.1 & Rendición de cuentas & Comparación & Analítica \\
& & Declaración & Testimonial \\
\hline
\end{tabular}

Fuente: Los autores.

\section{Fase 6. Matriz de hallazgos}

Una vez aplicadas las pruebas de auditoría, se elabora una matriz de hallazgos con todas las observaciones encontradas durante el proceso. En este apartado, a manera de ejemplo, se incluyen las observaciones identificadas durante la aplicación de la encuesta y la entrevista por cada dimensión (ver tabla 8). 


\section{CIENCIAMATRIA}

Revista Interdisciplinaria de Humanidades, Educación, Ciencia y Tecnología

Año VII. Vol. VII. N²2. Edición Especial II. 2021

Hecho el depósito de ley: pp201602FA4721

ISSN-L: 2542-3029; ISSN: 2610-802X

Universidad Nacional Experimental Francisco de Miranda (UNEFM). Santa Ana de Coro. Venezuela

Blanca Esthela Jumbo-Soto; Juan Carlos Erazo-Álvarez

Tabla 8.

Matriz de hallazgos .

\begin{tabular}{|c|c|c|c|c|}
\hline \multicolumn{5}{|c|}{ Asociación de Producción Textil NAPOTEX } \\
\hline \multicolumn{5}{|c|}{ Matriz de Hallazgos } \\
\hline \multicolumn{5}{|c|}{ Del 1 de enero al 31 de diciembre de 2020} \\
\hline \multicolumn{5}{|c|}{ Fecha de elaboración: julio 2021} \\
\hline Condición & Criterio & Causa & Efecto & $\begin{array}{l}\text { Recomendación y } \\
\text { fecha de } \\
\text { implementación }\end{array}$ \\
\hline $\begin{array}{l}\text { No existen } \\
\text { controles para } \\
\text { minimizar los } \\
\text { riesgos a los que } \\
\text { está expuesta la } \\
\text { asociación }\end{array}$ & $\begin{array}{l}\text { El manual de control } \\
\text { interno para las } \\
\text { asociaciones y } \\
\text { cooperativas no } \\
\text { financieras de la } \\
\text { economía popular y } \\
\text { solidaria, establece que } \\
\text { se debe cumplir con el } \\
\text { proceso de evaluación } \\
\text { de riesgos que incluye: } \\
\text { identificación, } \\
\text { valoración y respuesta. }\end{array}$ & $\begin{array}{l}\text { No se han } \\
\text { identificado } \\
\text { claramente los } \\
\text { riesgos a los que } \\
\text { está expuesta la } \\
\text { asociación. }\end{array}$ & $\begin{array}{l}\text { Riesgos } \\
\text { innecesarios } \\
\text { eventuales que } \\
\text { pueden generar } \\
\text { gastos } \\
\text { imprevistos. }\end{array}$ & $\begin{array}{l}\text { Recomendación: } \\
\text { Efectuar el proceso de } \\
\text { evaluación de los } \\
\text { riesgos de la } \\
\text { asociación tanto } \\
\text { interno como externo, } \\
\text { con el fin de } \\
\text { determinar controles } \\
\text { para minimizar dichos } \\
\text { riesgos. } \\
\text { Fecha: diciembre de } \\
2021 .\end{array}$ \\
\hline $\begin{array}{l}\text { Los miembros de } \\
\text { la asociación no } \\
\text { tienen } \\
\text { identificados } \\
\text { claramente a los } \\
\text { grupos de interés }\end{array}$ & $\begin{array}{l}\text { El documento de } \\
\text { ayudas de } \\
\text { procedimiento para el } \\
\text { llenado del formulario } \\
\text { de Balance Social indica } \\
\text { que se debe incluir a } \\
\text { los grupos de interés } \\
\text { (stakeholders) en las } \\
\text { decisiones o } \\
\text { actuaciones que realiza } \\
\text { una organización de la } \\
\text { economía popular y } \\
\text { solidaria. }\end{array}$ & $\begin{array}{l}\text { No se ha } \\
\text { profundizado } \\
\text { sobre la } \\
\text { importancia del } \\
\text { conocimiento de } \\
\text { los grupos de } \\
\text { interés como } \\
\text { pilares } \\
\text { fundamentales } \\
\text { en la consecución } \\
\text { de objetivos. }\end{array}$ & $\begin{array}{l}\text { Incumplimiento } \\
\text { de los } \\
\text { requerimientos } \\
\text { que establecen } \\
\text { los grupos de } \\
\text { interés para la } \\
\text { asociación } \\
\text { relacionados con } \\
\text { el ámbito social y } \\
\text { medioambiental. }\end{array}$ & $\begin{array}{l}\text { Recomendación: } \\
\text { Organizar un mapeo } \\
\text { de los grupos de } \\
\text { interés, identificar la } \\
\text { relación entre los } \\
\text { grupos de interés y la } \\
\text { asociación y } \\
\text { clasificarlos según su } \\
\text { orden de prioridad. } \\
\text { Fecha: diciembre de } \\
2021 .\end{array}$ \\
\hline $\begin{array}{l}\text { No se cuenta con } \\
\text { canales de } \\
\text { comunicación } \\
\text { abiertos }\end{array}$ & $\begin{array}{l}\text { El manual de control } \\
\text { interno para las } \\
\text { asociaciones y } \\
\text { cooperativas no } \\
\text { financieras de la } \\
\text { economía popular y } \\
\text { solidaria indica que } \\
\text { deben existir vías de }\end{array}$ & $\begin{array}{l}\text { Conocimiento } \\
\text { limitado sobre } \\
\text { sistemas de } \\
\text { información y } \\
\text { comunicación. }\end{array}$ & $\begin{array}{l}\text { Malos entendidos } \\
\text { que pueden } \\
\text { llegar a } \\
\text { rompimientos } \\
\text { sociales. }\end{array}$ & $\begin{array}{l}\text { Recomendación: } \\
\text { Crear una página web } \\
\text { de la asociación que } \\
\text { permita mantener una } \\
\text { comunicación estrecha } \\
\text { con las partes } \\
\text { relacionadas internas y } \\
\text { externas. }\end{array}$ \\
\hline
\end{tabular}




\section{CIENCIAMATRIA}

Revista Interdisciplinaria de Humanidades, Educación, Ciencia y Tecnología

Año VII. Vol. VII. N². Edición Especial II. 2021

Hecho el depósito de ley: pp201602FA4721

ISSN-L: 2542-3029; ISSN: 2610-802X

Universidad Nacional Experimental Francisco de Miranda (UNEFM). Santa Ana de Coro. Venezuela

Blanca Esthela Jumbo-Soto; Juan Carlos Erazo-Álvarez

\begin{tabular}{|c|c|c|c|c|}
\hline & $\begin{array}{l}\text { comunicación abiertos, } \\
\text { fiables y oportunos } \\
\text { para todos los grupos } \\
\text { de interés (internos y } \\
\text { externos). }\end{array}$ & & & Fecha: octubre 2021. \\
\hline $\begin{array}{l}\text { Desconocimiento } \\
\text { del nivel directivo } \\
\text { y socios sobre las } \\
\text { políticas y } \\
\text { actividades que se } \\
\text { deben } \\
\text { implementar para } \\
\text { la preservación del } \\
\text { medioambiente } \\
\text { como uno de los } \\
\text { objetivos } \\
\text { primordiales de la } \\
\text { asociación. }\end{array}$ & $\begin{array}{l}\text { En el artí́culo } 4 \text { de la } \\
\text { Ley Orgánica de la } \\
\text { Economía Popular y } \\
\text { Solidaria se describen } \\
\text { los principios que guían } \\
\text { las actividades de las } \\
\text { organizaciones bajo el } \\
\text { control de la SEPS, } \\
\text { entre los cuales está: la } \\
\text { responsabilidad social y } \\
\text { ambiental, la } \\
\text { solidaridad y rendición } \\
\text { de cuentas. }\end{array}$ & $\begin{array}{l}\text { Falta de } \\
\text { presupuesto para } \\
\text { llevar a cabo } \\
\text { actividades de } \\
\text { preservación } \\
\text { medioambiental. }\end{array}$ & $\begin{array}{l}\text { Posibles } \\
\text { sanciones por } \\
\text { parte del órgano } \\
\text { regulador. }\end{array}$ & $\begin{array}{l}\text { Recomendación: } \\
\text { Efectuar un plan de } \\
\text { actividades enfocado } \\
\text { en la preservación del } \\
\text { medioambiente en } \\
\text { donde participen tanto } \\
\text { las partes relacionadas } \\
\text { internas como } \\
\text { externas. } \\
\text { Fecha: diciembre } 2021 \text {. }\end{array}$ \\
\hline
\end{tabular}

Fuente: Los autores.

\section{Fase 7. Calificación de riesgos}

Con base en la matriz de hallazgos se debe realizar la calificación de riesgos que permitirá determinar el porcentaje de nivel de confianza y el riesgo de control. En la tabla 9 se propone una aplicación práctica.

\section{Tabla 9.}

Calificación de riesgos.

\begin{tabular}{|c|c|c|c|c|}
\hline \multicolumn{5}{|c|}{ Asociación de Producción Textil NAPOTEX } \\
\hline \multicolumn{5}{|c|}{ Matriz de calificación de riesgos } \\
\hline \multicolumn{5}{|c|}{ Fe enero al 31 de diciembre de 2020 elaboración: julio 2021 } \\
\hline No & Proceso & $\begin{array}{c}\text { Procesos } \\
\text { analizados }\end{array}$ & Calificación & Observaciones \\
\hline 1 & Talento Humano & 8 & 5 & $\begin{array}{l}\text { No hay controles para minimizar los } \\
\text { riesgos a los que está expuesta la } \\
\text { asociación. }\end{array}$ \\
\hline
\end{tabular}




\section{CIENCIAMATRIA}

Revista Interdisciplinaria de Humanidades, Educación, Ciencia y Tecnología

Año VII. Vol. VII. N². Edición Especial II. 2021

Hecho el depósito de ley: pp201602FA4721

ISSN-L: 2542-3029; ISSN: 2610-802X

Universidad Nacional Experimental Francisco de Miranda (UNEFM). Santa Ana de Coro. Venezuela

Blanca Esthela Jumbo-Soto; Juan Carlos Erazo-Álvarez

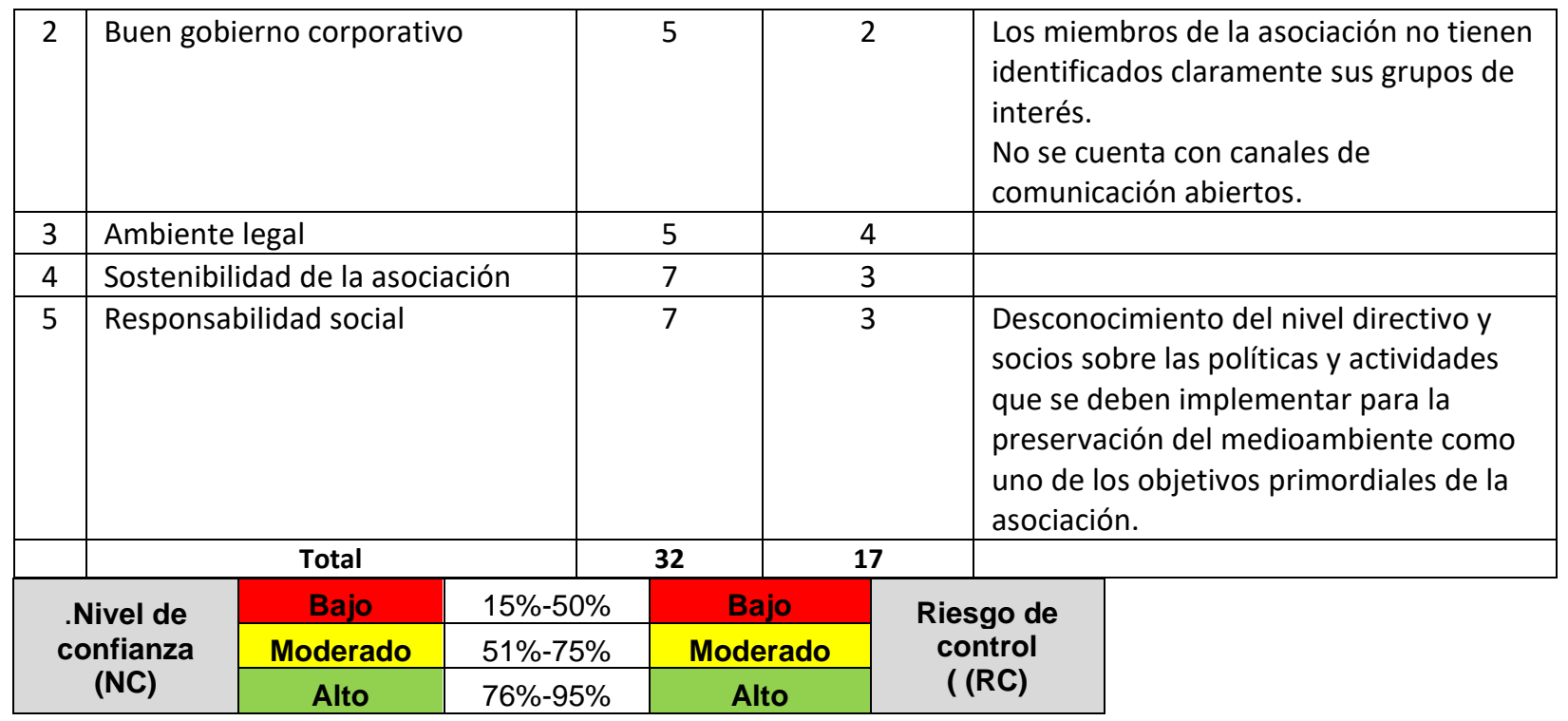

Calificación total (CT)

Ponderación total (PT)

Nivel de confianza

Riesgo de control
17

32

53\% Moderado

47\% Moderado

Fuente: Los autores.

Los resultados obtenidos determinan un nivel de confianza moderado y un riesgo de control moderado, siendo puntos a considerar las observaciones que se describen en la matriz de calificación de riesgos. 


\section{CONCLUSIONES}

La auditoría social es un proceso sistemático que permite evaluar el comportamiento social de una organización enfocada en los objetivos planteados para el grupo de interés, constituyéndose una herramienta indispensable para efectuar una rendición de cuentas efectiva que logre transparentar los movimientos realizados durante un período de tiempo determinado.

El desempeño organizacional constituye el resultado que obtiene una organización por la gestión de varios componentes, tales como el talento humano, buen gobierno corporativo, ambiente legal, sustentabilidad y responsabilidad social, a través del análisis de factores cuantitativos y cualitativos que guían a los grupos de interés hacia la toma de decisiones. El personal directivo y socios de la Asociación de Producción Textil NAPOTEX ASOPROTEXNAP reconocen que deben seguir trabajando para conseguir en su totalidad los objetivos sociales planteados, priorizando el aspecto social, económico y medioambiental, en razón de que existen debilidades relacionadas con la rendición de cuentas, identificación, evaluación y respuesta a los riesgos e identificación de las partes interesadas.

Es indispensable que los miembros de la asociación asimilen la gran importancia que conlleva la ejecución de una auditoría social como herramienta sistemática e integral para la medición del desempeño organizacional frente a los objetivos establecidos para sus grupos de interés, lo que permitirá transparentar los movimientos que realiza la organización y aplicar medidas correctivas ante las observaciones que se establezcan durante el proceso de la auditoría. 


\section{REFERENCIAS}

Aguinis, H., Villamor, I., \& Gabriel, K. (2020). Understanding employee responses to COVID-19: a behavioral corporate social responsibility perspective. Management Research: Journal of the Iberoamerican Academy of Management, 18(4), 421-438. http://dx.doi.org/10.1108/MRJIAM-06-2020-1053

Albert-Pires, M., Mourão-Arslan, L., Bayma-de-Oliveira, F., \& Puppim-de-Oliveira, J. (2020). Corporate social (ir)responsibility: an analysis of the disaster in MarianaBrazil. Scielo, 54(5). doi:https://doi.org/10.1590/0034-761220190153x

Arens-Alvin, A., Elder-Randal, J., \& Beasley-Mark, S. (2007). Auditoría. Un enfoque integral. [Audit. A comprehensive approach]. México: Pearson Educación. Obtenido de https://n9.cl/jhp3

Asociación Española de Contabilidad y Administración de Empresas. (2016). Responsabilidad social corporativa interna. Deliminación conceptual e información. [Internal corporate social responsibility. Conceptual delimitation and information]. Madrid. Obtenido de https://n9.cl/ea376

Benavides-Echeverría, I., Acosta-Padilla, C., \& Lozada-Orejuela, M. (2017). Auditoría Integral aplicada al sector público. [Comprehensive audit applied to the public sector]. Quito: Universidad de las Fuerzas Armadas ESPE. Obtenido de https://n9.cl/kditp

Bernal-González, I., Pedraza-Melo, N., \& Castillo-Hernández, L. (2020). El capital humano y su relación con el desempeño. [Human capital and its relationship to performance]. Revista Espacios, 41(22), 213-227. Obtenido de https://n9.cl/aw4uf

Berthin-Siles, G. (2011). A practical guide to social audit as a participatory tool to strengthen democratic governance, transparency, and accountability. Panamá. Obtenido de https://n9.cl/85avw

Buvollen, H., Mendoza, F., Reyes, A., \& Williams, S. (2006). Tejiendo paso a paso la auditoría social. [Weaving social audit step by step]. Guatemala: PNUD. Obtenido de https://n9.cl/hfe6r 
Coaquira-Tuco, C. (2018). Model for the improvement of organizational performance through the practices of quality management, knowledge management and transformational leadership in a private university. Apuntes Universitarios, 8(3). doi:https://doi.org/10.17162/au.v8i3.331

Daft, R. (2019). Teoría y diseño organizacional. [Theory and organizational design] (12 ed.). Ciudad de México: Cengage Learning Editores, S.A. de C.V. Obtenido de https://n9.cl/tgub

De-la-Garza-Carranza, M., Zavala-Berbena, M., \& López-Lemus, J. (2017). Competencias del emprendedor y su impacto en el desempeño organizacional. [Capabilities of Entrepreneurs and its Impact in Organizational Performance]. Universidad $y \quad$ Empresa, 53-74. doi:http://dx.doi.org/10.12804/revistas.urosario.edu.co/empresa/a.4811

Espinoza-Ortega, A., Narváez-Zurita, C., \& Erazo Álvarez, J. (2019). El control gubernamental a través de la auditoría de gestión bajo los ejes de transparencia, rendición de cuentas y participación ciudadana. [Government control through management audit under axes of transparency, accountability and citizen participation]. Cienciamatria, 5(1), 533-550. doi:https://doi.org/10.35381/cm.v5i1.279

Gil-Fabra, J. (2019). Aportes introductorios para un enfoque crítico sobre la auditoría de cuentas en la gobernabildiad neoliberal [Introductory contributions for a critical approach to audit in neoliberal governance]. Contabilidad y Auditoría(49), 105. Obtenido de https://n9.cl/4beaq

Gunjan-Kumar, P., \& Josyula-Prasuna, G. (2016). Social audit: current need in public health care sector. International Journal of Community Medicine and Public Health, 11-16. doi:http://dx.doi.org/10.18203/2394-6040.ijcmph20151543

Hernández, R., Fernández, C., \& Baptista, P. (2014). Metodología de la Investigación [Investigation methodology]. (Sexta edición ed.). México: Mc-Graw-Hill Interamericana.

Hernández-Madrigal, M. (2017). Sistemas de control de gestión y de medición del desempeño: Cconceptos básicos como marco para la investigación. [Management control and performance measurement systems: Basic concepts as a framework for research]. Ciencia y Sociedad, 111-124. Obtenido de https://n9.cl/tvqcc 
International Auditing and Assurance Satndards Board (IASSB). (2018). Manual of international procedures for quality Control, audit, review, other assurance orders and Related Services. Obtenido de https://n9.cl/vig2z

León, R., Gallegos, M., Vallejos, M., Guerrero, W., \& Acosta, B. (2020). Herramientas Gerenciales: Usos, Beneficios y Dificultades en su implementación en organizaciones de economía popular y solidaria [Management tools: uses, benefits and difficulties in their implementation in organizations of popular and solidarity economy]. Gestão e Desenvolvimento, $5 . \quad$ doi: https://doi.org/10.25112/rgd.v17i2.2014

Luque-González, A., Ordóñez-Salcedo, J., \& Ruales-Acosta, V. (2017). La responsabilidad social en las asociaciones de la economía popular y solidaria. [Social responsibility in the associations of the popular and solidarity economy]. ResearchGate, 2. Obtenido de https://n9.cl/m8lop

Ministry of Housing \& Urban Poverty Alleviation. (2017). Social Audit Guidelines. Obtenido de https://n9.cl/v4d8v

Montes, V. (2016). ¿Para qué el balance social?. [Why the social balance?]. En H. Jácome Estrella, \& e. al., Economía Solidaria. Historias y prácticas de su fortalecimiento (Primera ed., págs. 23-24). Quito: Publiasesores. Obtenido de https://n9.cl/ysczc

Moreno-Prieto, R. (s.f.). Los stakeholders y la Responsabilidad Social Corporativa. [Stakeholders and Corporate Social Responsibility]. Obtenido de https://n9.cl/etvz

Muthuveloo, R., Shanmugam, N., \& Teoh, A. (2017). The impact of tacit knowledge management on organizational performance: Evidence from Malaysia. Asia Pacific Management Review, 192-201. doi:http://dx.doi.org/10.1016/j.apmrv.2017.07.010

Ojeda-Hidalgo, J., López-Salazar, A., \& Álvarez-Orozco, D. (2019). ¿Influye la responsabilidad social en el desempeño organizacional? [Does social responsibility influence organizational performance?]. Estudios de Administración, 26(1), 16-34. doi:10.5354/0719-0816.2019.55404 
Poblador-Fernández, S., \& Porta-Jacques, F. (2017). El Balance Social como Herramienta de medición del impacto de la actividad empresarial en la sociedad. [The Social Balance as a tool for measuring the impact of business activity on society]. Obtenido de https://n9.cl/qqsl

Red de Economía Alternativa y Solidaria Euskadi (REAS). (2011). La economía solidaria en Euskadi: indicadores de auditoría social 2011. [The solidarity economy in the Basque Country: social audit indicators 2011]. Bilbao. Obtenido de https://n9.cl/iiviy

Red de Economía Alternativa y Solidaria Euskadi (REAS). (2020). Impacto del covid-19: la salida ESS en red. [Impact of covid-19: the networked ESS output]. Pamplona. Obtenido de https://n9.cl/0ilbx

Roy-Litzenberg, A., \& Carrie-Ramírez, F. (2020). Auditoría remota para COVID-19 y demás [Remote audit for COVID - 19 and more]. Obtenido de https://n9.cl/mvh8z

Sáenz-de-Ugarte, A. (2016). Auditoría Social: más allá de la cuenta de resultados [Social audit: beyond the income statement]. Pueblos - Revista de Información y Debate(71), 36-37. Obtenido de https://n9.cl/4g4w8

Salgado-Castillo, J., \& Calderón-Pinzón, L. (2014). Sistemas de control de gestión y desempeño organizacional: una revisión conceptual. [Management control systems and organizational performance: a conceptual review]. Obtenido de https://n9.cl/3xi2

Servicio de Acreditación Ecuatoriano. (2018). Diagnóstico social para procesos de mejora. [Social diagnosis for improvement processes]. Obtenido de https://n9.cl/5l83s

Superintendencia de Economía Popular y Solidaria (SEPS). (2020). Reglamento a Ley Orgánica Economía Popular y Solidaria. Obtenido de https://n9.cl/oqes

Ting-Peng, L., Jun-Jer, Y., \& Chih-Chung, L. (2010). A resource-based perspective on information technology and firm performance: a meta analysis. Industrial Management \& Data Systems, 110(8), 1138-1158. doi:http://dx.doi.org/10.1108/02635571011077807 
Villalba-Eguiluz, U., Arcos-Alonso, A., Pérez-de-Mendiguren, J., \& Urretabiskaia-Gil, L. (2020). Social and Solidarity Economy in Ecuador: Fostering an Alternative Development Model? Sustainability, 12-17. doi: http://dx.doi.org/10.3390/su12176876

Zhañay-Soliz, O., Erazo-Álvarez, J., \& Narváez-Zurita, C. (2019). Modelo de Auditoría de Sistemas de Información para las Cooperativas de ahorro y crédito del segmento 1, 2, y 3, de la ciudad de Cuenca [Information Systems Audit Model for Savings and Credit Cooperatives of Segment 1, 2, and and 3]. Cienciamatria, 361-393. doi:https://doi.org/10.35381/cm.v5i1.271

(C2021 por los autores. Este artículo es de acceso abierto y distribuido según los términos y condiciones de la licencia Creative Commons Atribución-NoComercial-Compartirlgual 4.0 Internacional (CC BY-NC-SA 4.0) (https://creativecommons.org/licenses/by-nc-sa/4.0/). 